\title{
DE LA SUBORDINACIÓN A LA COOPERACIÓN LABORAL: UNA ALTERNATIVA DESDE EL IGUALITARISMO CONSTITUCIONAL
}

From Subordination to Labor Cooperation: An Alternative from Constitutional Equalitarians

$\underline{\text { Wilson Yesid Suárez Manrique }}^{1}$

Fecha de recepción: 5 de octubre de 2016

Fecha de aceptación: 13 de diciembre de 2016

SUMARIO: 1. Introducción; 2. La desconfianza hacia el empleador; 3. La subordinación laboral; 4. Factores a tener en cuenta; 5. Las tres alternativas; 6. Referencias bibliográficas.

1 Doctor en Estado de Derecho y Gobernanza Global de la Universidad de Salamanca. Magister en Derecho de la Universidad Industrial de Santander. Profesor e investigador de la Universidad Santo Tomás Bucaramanga. Coordinador de la especialización en Derecho Constitucional y del Observatorio en Derecho Constitucional de la Universidad Santo Tomás. Código postal 681004, Dirección postal Calle 200 N 14-50. Correo-e: wilsonyesidsuarez@gmail.com 


\section{COMO SE CITA ESTE ARTÍCULO (APA 6)}

Suárez Manrique, Wilson Yesid (2017). De la subordinación a la cooperación laboral: una alternativa desde el igualitarismo constitucional. Revista Jurídica Mario Alario D’Filippo, IX (17), pág. 12-32.

\section{RESUMEN}

La subordinación laboral se constituye en uno de los axiomas del derecho laboral. Sin embargo, su revisión desde la perspectiva del igualitarismo constitucional, especialmente desde su concepción estructural, efecto perlocucionario y las exigencias democráticas, lo sitúa en entredicho. Los derechos fundamentales exigen una interpretación constitucional más plausible de esta figura. Como forma de superar las aporías que dicha tensión presenta, se propone como un candidato de remplazo adecuado, lo que en el presente texto se llama, "la cooperación laboral". Figura jurídica que, soportada en la dignidad humana y el respeto laboral, se presenta como una alternativa más racional, coherente, y jurídicamente más adecuada, que la subordinación laboral.

\section{PALABRAS CLAVES}

Subordinación laboral, igualdad, derecho constitucional, derechos fundamentales.

\section{ABSTRACT}

Labor subordination constitutes one of the axioms of labor law. However, their review from the perspective of constitutional egalitarianism, especially since its structural design, perlocutionary effect and democratic demands, puts into question. Fundamental rights require a more plausible interpretation of this constitutional figure. As a way to overcome the aporias that this tension presents, it is proposed as a suitable replacement candidate, which herein is called "labor cooperation". Legal concept that, supported on human dignity and respect labor, is presented as a coherent rational legally more appropriate, that alternative labor subordination.

\section{KEYWORDS}

Job Subordination, equality, constitutional law, fundamental rights. 


\section{INTRODUCCIÓN}

El presente artículo desea plantear los rasgos básicos de la cooperación laboral, como una forma de superar las deficiencias de la subordinación laboral y como una estrategia que permite organizar las relaciones laborales y dotarlas de un sentido coherente con los derechos fundamentales y en especial con la igualdad constitucional (Dworkin, 2003: 15). Especialmente, de lo que se trata es de proponer una forma de protección laboral, que no sea especialmente inductiva y formal, sino más bien, deductiva y material.

Esta propuesta parte de la respuesta constitucional a un problema presupuesto que no solo afecta la institución en estudio sino todas las estructuras en las que se cimienta el Derecho laboral. Este problema es el de la subordinación a la luz del igualitarismo constitucional y puede concretarse en la siguiente pregunta ¿Cómo ha de entender el igualitarismo constitucional la subordinación laboral?

A la subordinación laboral subyace la existencia de un poder, un sometimiento de una persona a otra. Como todo poder, implica la necesidad de su desconfianza (Ferrajoli, 2000: 121). A la subordinación pueden presentársele tres objeciones generales que minan su configuración clásica. Estas objeciones son: la estructural, la perlocusionaria y la democrática. Estas objeciones conllevan a mostrar como un candidato plausible para su remplazo, lo que en este escrito se llama "la cooperación laboral".

\section{LA DESCONFIANZA HACIA EL EMPLEADOR}

Uno de los axiomas en los que se ha sustentado el Derecho laboral es el de la subordinación del trabajador respecto del empleador. El empleador, de conformidad con los poderes derivados de la facultad de dirección y coordinación de la empresa, se encuentra en la capacidad de determinar la conducta del trabajador (Ackerman, 2005: 791); estos poderes son "una pluralidad de facultades que el ordenamiento jurídico reconoce como necesarias e indispensables para el funcionamiento normal de la empresa, para su organización económica, técnica y funcional" (Hernández, 1997: 405). Las facultades derivadas de la capacidad de dirección y mando en la empresa son una necesidad para el desarrollo adecuado de las funciones de la empresa (Baylos, 1999: 199). Ésta no podría desarrollarse de forma plausible, cumplir sus funciones, crecer y ser fuente de riqueza social, sino existiera una estructura organizada que permitiera coordinar esfuerzos, tomar decisiones importantes, direccionar las metas y adaptarse al entorno (Martínez, 1988: 376).

Sin embargo, a este principio, desde una perspectiva constitucional, pueden presentársele tres objeciones generales: la estructural, la perlocusionaria y la democrática. La objeción estructural refiere especialmente a asuntos relacionados con el alcance y el funcionamiento de la subordinación laboral. La objeción perlocucionaria alude al efecto 
que generan ciertas palabras, para el caso, al efecto negativo o peyorativo que pueden provocar en el destinatario (Austin, 1971). La objeción democrática, parte de una concepción amplia de democracia como forma de participación en toda clase de poder, la cual, por tanto, no se limita a la conformación y funcionamiento del poder público.

En cuanto a la primera objeción pueden revisarse tres situaciones: la falta de claridad en los alcances de las facultades derivadas, su abuso por parte del empleador y la ausencia de mecanismos para su defensa. Las formulaciones jurídicas con las cuales se conceden dichas facultades dejan amplios espacios de indeterminación normativa. Desde esa perspectiva se da el caso que el trabajador pueda verse obligado a efectuar labores que están por fuera del contrato de trabajo, tenga que efectuar actividades más allá de las debidas, deba sobrepasar el horario de trabajo, los días laborables y se encuentre en una situación de indefensión respecto de su patrono. La mayoría de las situaciones abusivas se conjugan bajo el principio del ius variandi (Cabanellas, 1963: 641).

Una de las formas que se han tomado para tratar de paliar esta situación es la de establecer por vía legal o jurisprudencial determinados límites a estas facultades. De forma legal se ha establecido por ejemplo en Colombia la Ley 1010 de 2006 sobre la protección al acoso laboral ${ }^{2}$. Mediante esta ley se desea, entre otras cosas, que el trabajador tuviera una órbita de protección de los abusos cometidos por el empleador; de forma específica el objeto de la ley es "definir, prevenir, corregir y sancionar las diversas formas de agresión, maltrato, vejámenes, trato desconsiderado y ofensivo y en general todo ultraje a la dignidad humana que se ejercen sobre quienes realizan sus actividades económicas en el contexto de una relación laboral privada o pública". Esta Ley define diferentes modalidades de acoso laboral, describe las conductas constitutivas del acoso, y establece medidas preventivas, correctivas y sancionatorias. Es un ejemplo interesante de la preocupación estatal por la protección del trabajador de los abusos del empleador, sin embargo, continua con la concepción clásica del trabajador subordinado que debe temor a su empleador y sigue efectuando un énfasis especial en las consecuencias más que en las causas.

Desde la perspectiva jurisprudencial se han trazado límites vagos derivados especialmente de la protección de derechos fundamentales al interior de la fábrica, por ejemplo, en la sentencia T 405 de 2007, la Corte Constitucional estableció la importancia de la obligación que tiene el empleador de respetar la intimidad, el buen nombre y la honra de sus trabajadores, especialmente, lo que concierne al trato respetuoso ${ }^{3}$. Las dos vías, la legal y la jurisprudencial, han sido importantes en cuanto al avance de la protección del trabajador, empero continúan siendo límites poco coherentes con perspectivas distintas

\footnotetext{
2 Por medio de esta ley se adoptan medidas para prevenir, corregir y sancionar el acoso laboral y otros hostigamientos en el marco de las relaciones de trabajo.

3 Cfr. Sentencias de la Corte Constitucional colombiana C 386 de 2000, C 934 de 2004, T 619 de 2013, C 593 de 2014, C 871 de 2014, C 237 de 2014, T 041 de 2014, T 899 de 2014.
} 
y no articuladas. La legal, es una protección a posteriori y fijada en las consecuencias, y la jurisprudencial es individual y discrecional ${ }^{4}$.

Los abusos parecen deberse a una especie de herencia socialmente aceptada de las servidumbres y los contratos de vasallaje de los cuales deriva de manera remota el contrato de trabajo ${ }^{5}$. En las servidumbres y los contratos de vasallaje existía una fuerte dependencia; el señor feudal ostentaba la potestad de disponer de la integridad y la vida de sus siervos, no obstante, se entendía que esa relación era beneficiosa para el siervo y éste debía obedecer a su amo en los aspectos personales y laborales. La relación laboral actual parece acordarse y transmitir implícitamente estas formas de derivación de lo que se había dado en un periodo de la historia. La subordinación del trabajador, si bien se encuentra en un eslabón más débil de dependencia, continua siendo una situación que presta un espacio propicio para el abuso.

En cuanto a la segunda objeción, los Tribunales Constitucionales se han mostrado muy sensibles respecto de ciertos términos o palabras que pueden generar en su destinatario una sensación peyorativa, de cierta forma discriminatoria, que atenta contra la dignidad de las personas. Así pues, la Corte Constitucional Colombiana ${ }^{6}$ determinó que debían remplazarse las palabras negritudes en la Constitución Política Colombiana por la palabra afrodescendiente, en la medida que el primer término podría entenderse con una carga semántica discriminatoria que afectaba la dignidad de este grupo de personas. En similar sentido, en el campo laboral, la Corte Constitucional colombiana en la sentencia C 037 de 1996 determinó que no debía hablarse de Departamentos de Recursos Humanos sino de Departamentos de Talento Humano, ya que el primer término instrumentalizaba a los trabajadores al tratarlos como medios. En la sentencia C 478 de 2003, la Corte determinó que el término patrono o siervo, eran inadecuados para referirse a esta clase de relaciones; el argumento general seguía siendo el respeto a la dignidad humana. Luego, en el caso de la subordinación, si se desea ser coherentes, tal situación también debería presentarse. La subordinación refleja una dependencia, una inferioridad de una persona sobre la otra, una forma de presentar en el ámbito privado la concepción de súbdito, que instrumentaliza a los trabajadores. Luego, esta forma de significar la relación, puede verse como un trato instrumental del trabajador.

La tercera objeción parte de una concepción amplia y finalista de la democracia. La democracia es una forma de participación en la conformación y en el ejercicio del poder, cuya finalidad es su repartición o limitación ${ }^{7}$. Pese a que tradicionalmente la democracia

4 En este sentido se hace importante la revisión de la sentencia de la Corte Constitucional Colombiana T 386 de 2009.

5 “Las tesis comunitarias encuentran su germen en la cultura jurídica germánica para la cual la relación de trabajo tenía sus orígenes en la relación de vasallaje o contrato de servicio fiel (Treudienstvertrag) —en oposición a la cultura romanista en la que la relación de trabajo se construye a partir de la locatio operarum, por la cual un hombre libre se comprometía a prestar servicio a otro, teniendo como antecedente a su vez la locatio hominis, a través de la cual el dominus cedía a otro el disfrute de un esclavo a cambio de un precio: «el hombre libre, locat se, se arrienda a sí mismo, como el señor arrienda a su esclavo, locat servum" Supiot (1994) pp. 25.

6 Corte Constitucional Colombiana sentencia C 253 de 2013.

7 Cfr. Constant (1989), p. 25. 
se ha mostrado como un instrumento para la participación en la conformación del poder político, en un sentido amplio, y teniendo en cuenta la existencia de poderes privados, resulta ser adecuado que la democracia se entienda como un instrumento que también obra en el campo privado, y que de ella se derivan ciertos derechos en favor de las personas. Luego, en este sentido amplio de la democracia los trabajadores tienen derecho en la formación y en el ejercicio de los poderes al interior de la empresa. Luego, la consideración de subordinados contradice esta concepción de democracia, al entenderlos únicamente como destinatarios de un poder externo.

Ahora bien, teniendo en cuenta las objeciones anteriores y aunque debe existir una dirección de parte de los empleadores de las funciones que desempeñan los trabajadores con miras a que puedan desarrollarse las actividades de forma más organizada al interior de la empresa, es claro que esta función pese a necesaria ha de ser limitada, y debe responder a las exigencias del igualitarismo constitucional. Una organización humana en la cual no exista una dirección que ayude a coordinar los esfuerzos mancomunados de las personas que en ella intervienen, no sería más que un desorden contraproducente que se guiaría por una especie de estado de naturaleza, pero que, al igual que como ocurre con el poder estatal, debe ser moderado.

Es decir, a la facultad de dirección, encajada mediante la subordinación laboral, debe establecérsele ciertos límites más o menos claros, en aras a determinar una mejor forma de protección en favor del trabajador. Lo anterior partiendo de la premisa que las facultades no sean apropiadas o defectuosas, puesto que una visión que argumente en favor del establecimiento del modelo actual, o que inclusive, defienda ideales según los cuales el poder del empleador debe ampliarse, no tendrían que revisar lo ya existente, sin embargo, la realidad social permite citar y tener como probadas las premisas referidas. La idea que se pretende exponer, en un grado de abstracción mayor, establece que el poder del empleador sobre el trabajador, que se tiene jurídicamente como algo benévolo, ha traído consecuencias negativas; consecuencias que pueden mejorarse con el establecimiento de estructuras que reconfiguren la forma clásica mediante la cual se ha entendido la subordinación en la relación laboral.

En lo que sigue trata de responderse a las siguientes preguntas ¿Se ha establecido una potestad demasiado alta en favor de los empleadores? ¿Se están dejando cosas muy importantes en manos de los particulares? ¿Podría plantearse una forma de entender la relación laboral de forma más proteccionista en favor del trabajador?

\section{LA SUBORDINACIÓN LABORAL}

La subordinación laboral es una clase de poder, un fuerte poder privado. No ha sido objeto de grandes reflexiones filosóficas, por prioridad y por preocupaciones más inmediatas. Sin embargo, como todo poder implica desconfianza, y bajo su manto se ha 
causado grandes daños sociales. Los cuales solo son relevantes en casos emblemáticos pero que afectan cotidianamente como las personas viven sus vidas. Puede asemejarse al poder estatal, desde la perspectiva que en el ámbito laboral se tejen micro regulaciones jurídicas y relaciones sociales, en las que se parangona una autoridad y un destinatario (Ferrajoli, 2006: 47).

Desde los inicios del Derecho laboral moderno, la potestad de mando que ostenta el empleador sobre los trabajadores se basó en la necesaria dirección y coordinación de la empresa. Sin esta facultad difícilmente podría establecerse un desarrollo empresarial adecuado, se hace necesario ostentar la preeminencia de una voluntad sobre las otras a efectos de direccionar esfuerzos. Visto desde la perspectiva del empleador hacia el trabajador se entendió que aquel ostentaba la facultad de dirección y mando, visto desde la perspectiva del trabajador, se entendió que el trabajador se encontraba subordinado al empleador. Estas dos situaciones son las dos caras de la misma moneda, mediante la cual se desea explicar en el sentido de quien se deberían desarrollar las actividades empresariales. Derivado de esa facultad de mando el empleador puede modificar las actividades, el horario, el modo, y de forma general, la forma como se desarrolla la relación laboral. En síntesis: el empleador impone su voluntad a la del trabajador.

Las consecuencias de que no existiese una especie de subordinación, o algo semejante, dentro de la relación laboral, serían poco deseables. La finalidad de la empresa no podría cumplirse: ¿si el trabajador pudiese escoger entre desarrollar, tales o cuales actividades la empresa podría prosperar? ¿Si no existieran lineamientos a seguir dentro de la fábrica los trabajadores se organizarían para el desarrollo adecuado de sus actividades? ¿Los trabajadores desarrollarían de buena fe sus actividades sin necesidad de un control cercano? El individualismo y el egoísmo son elementos que atentarían contra el transcurso de la empresa. Según la subordinación laboral las anteriores preguntas se responderían de forma negativa. Sin entrar al dilema del grado de subordinación que ostenta el empleador (teniendo en cuenta que la sujeción de una persona hacia otra puede ostentar los más variados niveles), parece plausible la necesidad que ésta exista.

El trabajador resulta ser, bajo esta perspectiva, un súbdito del empleador: debe obedecer sus órdenes, acomodarse a sus indicaciones, pues mediante un contrato se ha obligado a ello (Valdés, 1992: 29). Mediante el contrato de trabajo el trabajador cede al empleador parte de su libertad y capacidad intelectual y personal para situarla a su disposición. La subordinación de la relación laboral, que tiene su fuente en el contrato de trabajo, se funda en la idea general de la obediencia derivada de contratos feudales, vasallaje y de esclavitud. La diferencia entre estas tres figuras, lato sensu, es cuestión de grado y de afectaciones generales.

Este principio, a su vez, se funda en una organización jerárquica de las empresas, en la cual los trabajadores (los trabajadores masa), por lo general, ocupan el eslabón de base de la 
pirámide (Romagnoli, 1975: 197). Como se encuentra en el nivel más pobre de jerarquía su fuerte vocación de obediencia es una situación aceptada como norma social y jurídica -lo cual parece contrastar con el reconocimiento de los derechos constitucionales-. Además, son objeto de una constante regulación mediante diferentes estrategias de poder simbólico y real, que incluyen las más aceptadas e indirectas técnicas, las cuales, terminan por minar los espacios más íntimos de la vida personal del trabajador (BAYLOS, 1980: 307). Estos espacios incluyen temas tan íntimos que van relacionados con aspectos ideológicos y religiosos ${ }^{8}$.

El poder disciplinario del empleador se deriva del principio de subordinación, y mediante esta facultad el trabajador puede ser vigilado y castigado (Foucault, 2003) por el incumplimiento de las obligaciones contractuales. De forma general el trabajador puede ser despedido si desobedece las órdenes del empleador. Si un trabajador falta reiteradamente al trabajado o asiste en estado de embriaguez, se podría pensar que ha incurrido en una causal que constituye justa causa para terminar el vínculo laboral. Empero, qué ocurre ¿sí se trató de una orden que no se relacionaba directamente con el objeto contractual? ¿Sí el empleador deseaba que el trabajador incumpliera las ordenes emitidas? ¿Sí las órdenes dadas sobrepasaban las capacidades del trabajador o deberían efectuarse fuera del horario de trabajo? Más adelante se tratarán de resolver las anteriores preguntas.

Ahora bien, un campo más general en el cual puede verse la aplicación de la subordinación de forma más explícita, es el de la organización estatal paleolítica. En la organización estatal, para el desarrollo adecuado de la sociedad los miembros deben cumplir y sujetarse a los mandatos del soberano. El soberano podía bajo estas premisas dar cualquier tipo de órdenes a las cuales debían sujetarse los súbditos.

Actualmente no puede creerse que algún tipo de sociedad se organice con base en estos criterios. Especialmente, por la protección a los derechos fundamentales y la necesidad de participación en las formas de poder, su configuración y ejercicio. Las concepciones de la democracia mayoritaria o deliberativa, otorgan un mayor grado de participación de las personas en la toma de las decisiones estatales, las personas ostentan la facultad de tomar decisiones sociales, participar en los debates y ser activos dentro de la formación de la voluntad social. Inclusive, una decisión que no se halla basado en estos principios resulta ilegítima e invalida. En el ámbito familiar, también puede notarse un proceso de democratización similar, se elimina la concepción patriarcal y se les reconoce a los miembros familiares derechos de participación en las decisiones importantes que los afecten. Si esto es así, surge el cuestionamiento alrededor de por qué la estructura de la relación laboral parece no haber progresado en el mismo ambiente democrático o

8 Sin embargo, hay que tener en cuenta que la forma de organización compleja de las empresas conlleva a que al interior de estas existan diferentes jerarquías y diferentes niveles de subordinación. Luego existen trabajadores respecto de los cuales el principio de subordinación se aplica con menor fuerza, piense en los gerentes o directores de las empresas, empero existe otra clase de trabajadores, que son la mayoría, respecto de los cuales el principio se aplica con mayor ímpetu. 
por qué debe creerse que ese tipo de relaciones es la mejor forma de desarrollar el establecimiento de un poder sobre los otros ${ }^{9}$.

Contrario a las sugerencias de las preguntas anteriores, los empleadores han aumentado el poder y desean buscar la forma de seguir acaparándolo ${ }^{10}$, mientras tanto los trabajadores, en el polo opuesto, derivado de la costumbre, el desempleo, la poca capacitación, los bajos niveles de seguridad social, y de la falta de empleos bien remunerados, continúan sometidos a este yugo ${ }^{11}$. Los empleadores aumentan el poder entre otras cosas, por el correlato de las situaciones anteriores y por los adelantos tecnológicos, que permiten una mayor intromisión en la órbita del trabajador en la empresa, permiten mayor inspección, control en el desarrollo de las actividades, en la producción y en el manejo de la producción (Aparicio, 1992: 9).

Si bien se hace necesario el establecimiento de un poder de coordinación para el desarrollo adecuado de las funciones de la empresa y al mismo tiempo se teme de la forma en la que se ha desarrollado éste, cabe preguntarse ¿Cuál es la forma adecuada para coordinar el desarrollo de las actividades en la empresa? ¿Cómo puede desarrollarse una forma de protección al trabajador que al mismo tiempo reduzca la posibilidad de que se abuse de ella?

Para responder a las anteriores preguntas se hace necesario describir tres alternativas para el manejo de las relaciones laborales al interior de la empresa. Posteriormente, esas alternativas son valoradas y criticadas a efectos de establecer cuál de esas alternativas ofrece la concepción que mejor interprete el igualitarismo constitucional y proteja de forma más adecuada al trabajador. Antes de exponer las alternativas se han de tomar en cuenta cuatro factores que inciden en la valoración que se efectuará.

\section{FACTORES A TENER EN CUENTA}

Para responder a las preguntas acerca de la subordinación del trabajador en el marco del contrato de trabajo y plantear alternativas plausibles se hace necesario tener en cuenta, por lo menos, cuatro asuntos importantes: la pertinencia jurídica de la figura, el grado en el cual debe ejercerse, los beneficios generales y los sujetos involucrados.

\footnotetext{
9 La forma en la que los empleadores manejan la potestad de mando es insensible al principio de reciprocidad. Los empleadores no tomarían decisiones que a ellos les favorecería si fueran trabajadores. Las decisiones que el empleador toma respecto de sus trabajadores, por situar un ejemplo que puede ilustrar la idea que se defiende, no son decisiones que el empleador le gustaría que el estado tomara respecto de él. El aumento de la vigilancia que ejerce el empleador le resultaría odioso si eso implicara un aumento de la vigilancia por parte del estado, el trato de "acomódese o vallase" no es el mismo que le gustaría sentir en materia tributaria respecto del estado.

10 Así, la empresa y las facultades de dirección del empresario permanecen "inmunes a los presupuestos básicos de un sistema democrático". (Molina, 1999: 366).

11 Podría pensarse que no existe la obligación de los trabajadores de mantener una relación laboral cuando las condiciones no son adecuadas, que la decisión que ellos deberían tomar es cambiar de actividad y buscar otra en la cual estén mejor remunerados y el trato que reciben del empleador sea más adecuado. Una respuesta de este tipo resulta atractiva pero es insensible a las circunstancias laborales de países como España y Colombia. Las causas principales para que no se proceda de esta forma son el alto nivel de desempleo, la baja velocidad de rotación del empleo y la necesidad del trabajador de los ingresos derivados del empleo.
} 
En primer lugar, la pertinencia de la figura de la subordinación refiere a la pregunta relativa a si es necesario el establecimiento de esta figura, es decir, si es una condición sine qua non para el adecuado desarrollo de las relaciones laborales. La respuesta a esta pregunta puede ostentar diferentes versiones, desde las concepciones conservadores, según las cuales debe mantenerse de la forma en la que se ha desarrollado, y las respuestas liberales, que podrían plantear el cambio de la figura por una estrategia que permita de mejor forma la protección de los derechos de los trabajadores: la reducción del poder del empleador conlleva una mejor protección de los trabajadores. No obstante, que existan distintas versiones acerca de las respuestas a esa pregunta, es necesario tener en cuenta que en lo que sí coinciden es que difícilmente pueda plantearse la eliminación total de la figura; aún en los casos extremos se haría necesario plantear un principio de respaldo, como la buena fe, que permita, así sea en un grado mínimo, una meridiana organización empresarial y un desarrollo económico como fin constitucional.

En segundo lugar, en caso de aceptar que la figura debe seguir existiendo, bien sea de la misma forma o con modificaciones, es importante reflexionar acerca de la fuerza en la que debe ser ejercida, dentro de los diferentes grados de poder que puede ejercer una persona sobre otra (Hart, 2004) ¿Cuál es la forma más adecuada en la que debe desenvolverse el poder de mando en la relación laboral? En este sentido, podría pensarse que es posible establecer un nivel de categorías que permitan diferenciar el grado de poder con el que se dirige una empresa, por ejemplo, en el sentido de afirmar que en una empresa puede establecerse una fuerza: alta, media o baja. Esta escala puede enriquecerse de muchas formas, por ejemplo, estableciendo escalones entre los diferentes niveles o creando una tabla más completa con otras variables, o estableciendo situaciones de excepción.

En tercer lugar, ha de pensarse en las consecuencias que tienen el establecimiento de la figura o su modificación. Es decir, como se afecta la sociedad, la empresa, el trabajador, e inclusive, el estado, cuando se opta por una u otra forma de coordinar las relaciones laborales dentro de la empresa; como se afectan los derechos de las personas y los grupos. Lo anterior parte de la hipótesis que dependiendo de la forma en la que se pretenda organizar las relaciones laborales ello traerá consecuencias benéficas para el empleador: como mayor grado de pertenencia, mayor flujo intelectual e iniciativa (Ojeda, 2010: 225); o consecuencias negativas: como falta de motivación de los trabajadores, altos costos de cooperación, mal ambiente laboral, etc.

En cuarto lugar, se hace importante revisar la forma en la que la figura se puede ejercer en relación con determinadas clases de trabajadores. Es decir, intuitivamente se parte de que la subordinación, o figura afín que se plantee, debe tratar con una especial consideración a determinados trabajadores, que son más vulnerables que otros. El grado de indefensión con que cuentan los trabajadores es distinto, pareciera ser que existen trabajadores que necesitan una especial consideración derivado ello de sus condiciones, 
sociales, culturales, económicas o educativas. En algunos casos depende inclusive de la voluntad del empleador direccionar su conducta y decisiones en sentido de igualdad.

\section{LAS TRES ALTERNATIVAS}

Las tres alternativas que se describen a continuación tienen en cuenta los factores anteriores y muestran fórmulas distintas para sobrepasar la clásica forma de entender la subordinación laboral. Con la finalidad de escoger cual puede ser la que mejor se acomode a las exigencias de los modernos constitucionalismos. La concepción clásica de la subordinación se encuentra inserta dentro del modelo del Estado Liberal (Sachica, 2000: 87), y se identifica, especialmente con los principios de libertad, propiedad y libertad de empresa (Duguit, 1987), en la medida que acepta la voluntad de las partes como fuente de subordinación de una persona respecto de otra.

Las dos primeras alternativas siguen estrategias similares a las establecidas para limitar el poder estatal en relación a disminuir el poder del empleador, bien sea respecto de reglar sus funciones o limitar su campo de acción. La primera alternativa es entender la subordinación como algo odioso dentro del contrato y, por tanto, modificar totalmente el concepto desde la perspectiva de establecer dentro del contrato una intromisión fuerte del Estado, en la medida en que se exija que las actividades y las obligaciones que debe cumplir el trabajador se describan de forma detallada dentro del contrato, luego, la relación laboral se desarrollaría dentro del cumplimiento específico de lo estipulado. Esta alternativa tiene una especial inspiración en el principio de legalidad estatal.

La segunda alternativa consiste en permitir el desarrollo libre del trabajador al interior de la empresa, teniendo en cuenta el principio de buena fe del trabajador y que éste cumplirá las labores encomendadas de una forma adecuada. Esta concepción es similar, teniendo en cuenta las diferencias en el campo de aplicación, a la concepción del Estado Mínimo, y también, se encuentra inspirada en la necesidad de concebir al trabajador un mayor poder de participación en las decisiones de la Empresa, luego, se encuentra relacionada con la concepción del Estado Democrático (Habermas, 1998: 125). La tercera alternativa consiste en modificar la noción de subordinación por la de cooperación laboral, según la cual los trabajadores ostentan una participación de socios activos dentro de la empresa lo cual permite democratizar la empresa y participar en la formación y toma de decisiones laborales. Esta alternativa se inspira especialmente en las concepciones del Estado Constitucional y Democrático.

La primera alternativa parece plausible y con beneficios deseables. El hecho de que se establezcan al interior del contrato de trabajo de forma detallada las obligaciones que deben cumplirse, y se especifiquen en cuanto al tiempo, modo y lugar, se presenta como una solución que podría parecer atractiva. No es imposible, en la medida que sigue la senda del contrato de prestación de servicios (Corte Constitucional Colombiana, 2012: 
C 171). Esta alternativa tiene la potestad de restringir de manera importante el poder de mando del empleador sobre el trabajador, es desconfiada de esta facultad y de la forma como se ha ejercido, y establece una vía para la reducción del abuso. Así pues, se desea cambiar la figura clásica de la subordinación, y, en lo posible reducir el poder del empleador.

Además, puede verse beneficiosa para el trabajador por cuanto de forma pretérita el sabría cuáles son las actividades que debe desarrollar dentro de la relación laboral y, por tanto, de antemano tendría conocimiento de cuáles son sus obligaciones. No correría el riesgo de verse sorprendido por las indicaciones y orientaciones que emita el empleador. El hecho que desde el principio de la relación laboral se delimiten las obligaciones del trabajador es una forma de respetar su autonomía (Calderón, 2011) y considerarlo en mejor grado de igualdad respecto de su empleador (nadie celebraría un contrato para edificar una casa si no supiera cuales son las dimensiones y la forma de la edificación). Esta hipótesis de trabajo, inclusive, traería beneficios a favor del empleador: eliminaría costos al empleador en la administración de las capacidades de los trabajadores, podría efectuar un mejor control de las actividades desarrolladas por sus empleados, y permitiría efectuar una planeación detallada de las actividades de la empresa. El Estado, podría pensarse, también se vería beneficiado, en la medida que se eliminarían las reclamaciones entre trabajadores y empleadores por el abuso de la facultad de coordinación, en especial, podrían eliminarse gran parte de los litigios derivados del alcance y las tareas por cumplir en el desarrollo del contrato de trabajo.

Sin embargo, esta forma de entender la relación ostenta inconvenientes insalvables: los costos del contrato completo (Cooter y Uler, 2000), la imposibilidad cognitiva (Bernal, 2009), la rigidez y la ambigüedad normativa (Alexy, 2002). El establecimiento del contrato completo sería muy costoso, en la medida de prever todas las eventualidades que pueden darse en la ejecución del contrato se hace muy difícil y conlleva la inversión de una cantidad considerable de tiempo, dinero y esfuerzo. Es mucho más económico para el empleador redactar contratos generales de trabajo en el cual se guardé para sí el direccionamiento de las funciones específicas. Tratar de establecer un contrato completo, además de los costos que acarrea, presenta un problema epistémico de imposibilidad de establecer las distintas variables y situaciones que pueden llevarse a cabo en la ejecución e interpelación del contrato. Es imposible, por el dinamismo y la cantidad de situaciones, hechos y procesos, que pueden presentarse en el desenvolvimiento del contrato, prever todos los pormenores importantes a la relación para regularlos en los contratos. No obstante, si ello pudiera hacerse, en última instancia conllevaría a restarle flexibilidad a la empresa en su conjunto y capacidad de respuesta respecto de los estímulos y transformaciones sociales.

La economía de mercado hace necesario para el desarrollo adecuado de la empresa que esta se pueda adaptar a su entorno (Ojeda, 2010: 48), lo cambiante de los negocios, la 
vida liquida ${ }^{12}$ empresarial, hacen necesario que exista flexibilidad en el desarrollo de las actividades comerciales. Además de estos inconvenientes, se encuentra el hecho que la ambigüedad del lenguaje conllevaría para el ejercicio o el cumplimiento adecuado de las obligaciones estipuladas. A las estipulaciones contractuales le ocurren los mismos males que las disposiciones constitucionales y legales: adolecen de ambigüedad semántica. Por lo cual, no es fácilmente adscribible el conjunto de significados a las disposiciones contractuales, lo cual, llevaría a interminables discusiones sobre las interpretaciones de las reglamentaciones contractuales.

Por su parte, la segunda alternativa, que sigue la misma vía relativa al Estado Mínimo, que tiene por finalidad salvaguardad la libertad estableciendo espacios infranqueables al poder, pese a que en principio parecería liberar al trabajador del yugo del empleador, tampoco parece ser del todo plausible como modelo para remplazar la concepción tradicional de la subordinación. En principio sigue la línea de limitar el poder del empleador, empero, obra no sobre la constitución del contrato sino sobre su ejecución.

Según esta visión, que se fundamenta en aspectos liberales extremos, la mejor forma de proteger al trabajador del empleador es lograr la eliminación de la figura tal como la conocemos, y confiar en el trabajador y en la buena fe para el desarrollo adecuado de sus labores. Esta concepción permite mayor libertad del trabajador en la empresa, mayor dinamismo, mejor flujo de ideas y es especialmente benéfica en cuanto al establecimiento de un espacio libre de intromisiones externas provenientes del empleador. También resultaría benéfica al empleador en la medida en que se ahorraría costos de construcción del contrato, costos administrativos para el desarrollo de las actividades y la vigilancia del trabajador, y puede verse beneficiado en el incremento del potencial creativo de sus trabajadores que repercute en beneficios empresariales (Ojeda, 2010).

No obstante, esta forma de ofrecer una alternativa a la concepción actual de la subordinación presupone un modelo de organización social y económica diferente, inclusive, presupone un trabajador distinto al existente en las sociedades españolas y colombianas. Los trabajadores como cualquier persona no son ni ángeles ni demonios (Hart, 2004: 48). Tienen inclinaciones para obrar hacia el bien y hacia el mal, sería muy ingenuo, entonces, pensar que su comportamiento dentro de la empresa va a ser el mejor que se pudiera esperarse. Los contextos culturales, educativos y de tono económico han formado un tipo de persona individualista, preocupado principalmente por la satisfacción de sus necesidades, y que difícilmente desea esforzarse, tener iniciativa o proponer actividades que le impliquen un mayor esfuerzo. Las consecuencias que podrían preverse bajo estas premisas son de caos total en la empresa, los trabajadores no están preparados ni formados para afrontar esta manera de concebir la estructura laboral ni asumir las responsabilidades que de ella derivan.

12 "La modernidad sólida y sus múltiples características parecen tan lejanas a la actualidad donde lo característico es precisamente lo contrario: lo efímero, lo mutable y lo impredecible." (Bauman, 2006: 10). 
Este modelo no pone tanto en peligro la libertad del empleador sino especialmente la existencia de la empresa. Asimismo, en últimas, iría en contra del propio trabajador, al situar en peligro la viabilidad de la empresa y por ende su posibilidad de derivar beneficios de ella.

Como tercera alternativa se plantean las ideas básicas de la concepción de "cooperación laboral". El planteamiento de la "cooperación laboral" sigue dos líneas argumentativas: supera las objeciones que se le presentan al principio de subordinación laboral, y se cimienta en la interpretación más plausible del constitucionalismo contemporáneo, especialmente del principio de igualdad, los derechos democráticos y de la dignidad humana ${ }^{13}$. Una de las principales finalidades de esta noción es la de la transformación de la clásica concepción de subordinación en la relación laboral, propia de un modelo liberal del estado, que permite reducir el abuso del poder y que, al igual que ha ocurrido en otros campos, debe reconfigurarse para ofrecer una perspectiva jurídica más coherente con el desarrollo constitucional contemporáneo.

Al principio de cooperación laboral no pueden realizársele las mismas objeciones que se le plantearon a la subordinación laboral. En primera lugar, no puede considerarse que genere un efecto perlocucionario (Austin, 1971) que atente contra la dignidad del trabajador. Pues, éste no se entiende como un subordinado, como alguien que dependa de la voluntad de otra persona, sino como un cooperado; una persona que merece consideración y respeto dentro de la relación laboral. Se ensalza su valor dentro de la empresa, se reconoce la importancia de su persona y el valor intrínseco de que es portador. En segundo lugar, es coherente con un rol más activo dentro de la Empresa, acorde con el reconocimiento de los derechos democráticos, y con una visión amplia de la democracia (Dworkin, 2003: 85), como un mecanismo en la consolidación y ejercicio en toda clase de poder, a la vez que limita el poder del empleador. Los problemas estructurales de la subordinación laboral, en tercer lugar, también se ven disminuidos, en la medida en que se limita y reparte el poder (Dworkin, 1993).

El principio en comento tiene especialmente dos premisas de partida: la desconfianza al poder y la necesidad de coordinación de las relaciones laborales. Presenta una seria desconfianza hacia la forma clásica como se ha entendido la subordinación y el control que ostenta actualmente el empleador, y no cree en la buena fe para el desarrollo de las actividades por parte de los trabajadores. Luego, trae, como consecuencia, la inconveniencia de considerar constitucional la forma tradicional de entender la subordinación laboral ${ }^{14}$.

13 Es decir que la cooperación dentro del contrato de trabajo descansa en una concepción democrática e igualitaria de la relación laboral en la cual los trabadores participan de forma activa y libre en el desarrollo de las actividades de la empresa. Con esta figura se desea ofrecer una interpretación democrática de la dirección de la empresa, acorde con los postulados del constitucionalismo democrático y de la especial consideración y respeto de que son titulares los trabajadores.

14 De esta forma la pregunta de si es constitucional el entendimiento de la subordinación laboral de la forma como lo ha entendido la doctrina laboral clásica, según el principio de cooperación laboral, tendría una respuesta negativa. El igualitarismo constitucional y los derechos democráticos se encuentran en tensión con la forma como se ha entendido la subordinación laboral, no desde la perspectiva 
Los principales argumentos que cuestionan la forma clásica en la que se ha entendido la subordinación laboral, y que se derivan de las objeciones planteadas, pues corresponden a su traducción o especificación, son los siguientes: el establecimiento de una subordinación (fuerte) de una persona respecto de otra trasgrede el igualitarismo constitucional, el abuso de la posición de superioridad del empleador respecto del trabajador (en la medida que es permitida por el ordenamiento jurídico), la falta de límites claros entre las indicaciones de trabajo y el abuso de ellas, la falta de un principio rector que articule la forma de entender la relación, la poca capacidad de participación que esta forma de entender la relación conlleva, la herencia socialmente aceptada del vasallaje y la servidumbre ${ }^{15}$, los cambios que se han dado en estructuras análogas (que si bien presentan elementos diferenciadores importantes, no por ello puede negarse su aspecto normativo en relación a la modificación han ostentado las relaciones políticas o familiares) y la concepción activa en la formación, deliberación y toma de decisiones importantes.

La cooperación laboral se muestra como forma más plausible de interpretación de las disposiciones iusfundamentales. Presenta menor sometimiento a las decisiones del empleador y mayor participación en la toma de decisiones. El poder del empleador se ve mermado al reconocer en el trabajador una persona que merece una igual consideración y respeto, que no se trata de un subordinado que se encuentra obligado a conceder y cumplir sus caprichos, sino que es una persona portadora de derechos fundamentales y democráticos que deben hacerse valer al interior de la fábrica ${ }^{16}$.

La cooperación está estructurada de la siguiente forma: ostenta un núcleo, una órbita cercana y una órbita general. En cuanto al núcleo, que corresponde a las decisiones necesarias que regulan la relación laboral, entiende la toma de decisiones importantes que tienen como médula las reglamentaciones de las exigencias de los derechos fundamentales y la dignidad humana. Este núcleo está vedado a las decisiones del empleador o de los trabajadores.

\footnotetext{
de que no sea necesaria sino desde el punto que conlleva un sometimiento desproporcionado por la prestación de servicios personales que por lo común y antiguo no debe sostenerse, sino que debe evaluarse conformidad con las exigencia iusfundamentales, además que ha sido la causa de grandes afectaciones los derechos fundamentales. Los derechos fundamentales se han visto más afectados por las decisiones de los empleadores que directamente por la influencia de factores económicos. Asimismo, la subordinación es un poder con límites pocos claros que resulta lesivo para el reconocimiento y protección de los derechos al interior de la fábrica y que se presenta, pese a los avances jurídicos en ese sentido, como un espacio de oportunidad para el abuso que por lo general es aceptado y tolerado por el trabajador por el miedo a la pérdida del empleo, del que, se entiende, deriva su subsistencia.

15 Esta forma de concebir la relación en la cual se somete a una persona a los dictados de otra por una suma de dinero, en principio, parece ser sospechosa. Lo que pasa es que es una situación que se ha heredado socialmente y que parece tan natural que ello conlleva a que no se revisen los verdaderos alcances que puede presentar esta forma de vasallaje moderno. En este punto, parecería que ha faltado una reflexión jurídica en torno a los puntos clásicos en los que descansan la mayoría de las instituciones jurídicas; que una estructura se halla mantenido por mucho tiempo como pieza jurídica importante no es un argumento claro en torno a su validez o vigencia, antes bien, puede verse como un argumento en favor de su reforma y reconstrucción de conformidad con las exigencias constitucionales contemporáneas.

16 Para establecerlo en términos franceses "poner en relación los conceptos de autoridad y democracia en el marco de la empresa es involucrarse en el tema de la ciudadanía en la empresa". (Aparicio,1992).
} 
Por fuera de este núcleo se encuentran las decisiones importantes para el funcionamiento de la empresa, las cuales corresponden a la "órbita cercana", que se inspiran en el núcleo pero en la cual tiene influencia importante las decisiones organizativas del empleador, decisiones importantes y necesarias para el desarrollo adecuado de la empresa ${ }^{17}$. Son una especie de márgenes de acción del empleador ${ }^{18}$, que en forma general pueden corresponder a la fijación de fines de la empresa, y medios para cumplirlos, en los cuales el contrato de trabajo ostenta un papel importante.

La orbita general corresponde a la regulación de los aspectos en los cuales se hace necesaria una participación activa del trabajador en desarrollo especialmente de sus derechos fundamentales ${ }^{19}$; son unos márgenes de acción a favor del trabajador que garantizan mayor participación de éste dentro de la empresa, los cuales se desenvuelven en distintas etapas de la relación laboral. Por ejemplo, el caso de la regulación de la conciliación de la vida familiar ${ }^{20}$, la consolidación de los departamentos de Gestión del talento Humano (Corte Constitucional Colombiana, 1996: C 037), los derechos de estudio $^{21}$, el ejercicio de los derechos religiosos ${ }^{22}$, o la democratización de la empresa ${ }^{23}$.

Por último, quedan por señalar tres ideas generales, que ayudan a reforzar la idea de la cooperación laboral: la sugerencia de la búsqueda de la completud del contrato laboral,

17 En relación con la potestad del empleador de establecer cargas a los trabajadores se entiende que el principio de la cooperación respetuosa no deja por fuera la facultad de mando o coordinación que debe existir en sociedad, sino que simplemente la reduce a su expresión elemental en el entendido de que debe ejercerse con desconfianza pero sin perder de vista su necesidad para el desarrollo empresarial. Se trata del ejercicio de una facultad ejercida de forma responsable, entendiendo la exigencia de respeto que se debe al trabajador.

18 Para Alexy la constitucionalización adecuada del derecho conlleva a que la constitución regule aspectos importantes que debe reglamentar en la vida jurídica pero al mismo tiempo deje ciertos márgenes de acción al legislador. Principalmente, estos márgenes de acción pueden ser epistémicos o estructurales. Los márgenes de acción epistémicos refieren a la capacidad cognitiva para reconocer lo que la constitución permite, ordena o prohíbe. "Si se quiere afinar el planteamiento, puede decirse que el margen de acción epistémico deriva de los límites de la capacidad para reconocer los límites de la Constitución". (Alexy, 2004: 28).

19 Las personas racionales no elegirían una eliminación completa de las reglas de organización y cooperación al interior de la relación laboral por cuanto esto traería desorden y descontrol al interior de las relaciones laborales y en últimas se afectaría al trabajador. Pero tampoco elegirían una extrema situación de subordinación del trabajador de la forma como se ha desarrollado tradicionalmente. Se debe buscar establecer un punto que permita la coordinación de las actividades sin que ello implique correlativamente el sacrificio de los derechos de los trabajadores.

20 Reforma Laboral aprobada por el Real Decreto-Ley 3/2012 mediante el cual se toman medidas para favorecer la conciliación entre la vida laboral, familiar y personal.

21 El Tribunal Supremo de España reconoce el derecho de los trabajadores que simultáneamente adelantan estudios y trabajan a elegir turno de servicio, si en su empresa existe esta modalidad de distribución del trabajo. Según el Tribunal tanto la Constitución como el Estatuto de los Trabajadores 'hacen prevalecer, salvo prueba en contrario, el ejercicio de los trabajadores de su derecho a promoción profesional, y en tal sentido, no es aceptable limitar el alcance y el efecto de las normas que reconocen tal derecho más allá de lo razonable, mediante una interpretación restrictiva que no encuentra justificación alguna'.

22 La Corte Constitucional Colombiana en la Sentencia T 237 de 2009, sostuvo, con base en el derecho a la libertad de conciencia y de cultos, que el derecho fundamental a la libertad religiosa "incluye la protección de guardar un día de descanso para la adoración de Dios cuando ésta constituya un elemento fundamental de la religión que se profesa y la creencia de la persona es seria y no acomodaticia". Por tal razón la decisión del empleador de despedir a un empleado por no ir a trabajar los sábados, "desconoce el derecho a la libertad religiosa del trabajador" y por tanto "la limitación del derecho fundamental no se encuentra constitucionalmente justificada". Cfr. Sentencias de la Corte Constitucional colombiana T 123 de 1999, T 026 de 2005, T 327 de 2009, T 493 de 2010, T 982 de 2001.

23 La Corte Constitucional Colombiana en sentencia C 1260 de 2001 dispuso: "La Constitución, al adoptar la fórmula política del Estado Social de Derecho, propugna por la democratización de la propiedad, que tiene como objeto generar condiciones propicias para permitir que ciertos grupos tengan acceso a ésta más fácilmente. Esta opción constitucional se materializa en diversas normas constitucionales, y en especial en el artículo 60, el cual, como esta Corte lo ha señalado, contiene dos mandatos diferenciados, pues simultáneamente establece un principio general y una regla." Cfr. Sentencia Corte Constitucional colombiana T 125 de 1994. 
la especial protección que deben ostentar los trabajadores más desprotegidos, y las consecuencias generales de la noción en gloso. El contrato de trabajo debe ser lo más completo posible, sin que ello conlleve a la exigencia de plena completud, se debe tratar de reducir al máximo el poder del empleador, en la medida que la posibilidad de emitir ordenes e indicaciones de las que pueda abusar se aminore.

Actualmente las legislaciones permiten la celebración de los contratos con pocos requisitos, entre los cuales no se establece la especificación de las funciones que debe cumplir el trabajador. No sobra tener en cuenta que los costos de redacción del contrato pueden influir en la celebración del contrato, pueden conllevar a reducir el número de contratos que se celebran. Sin embargo, esta situación sucede especialmente cuando los costos son muy elevados, los costos moderados de un contrato no son de tal envergadura que conlleven a cambiar radicalmente la intensión de contratar o a exigir una inversión desproporcionada, se trata de una situación que repercute en beneficio del empleador. Esta exigencia de completud moderada no implica de por si la negación de la posibilidad de celebrar contratos con poca especificación, en este caso el responsable y quien debe asumir las consecuencias de ello es el empleador.

El mayor grado de subordinación de la relación laboral se hace en los trabajadores que se categorizan en los extremos de las edades productivas (jóvenes o personas de la tercera edad) y en las actividades peor remuneradas. En la mayoría de los casos ello se conjuga con la precariedad en el empleo y con la falta de una remuneración adecuada. Es decir, aunque suene paradójico, los trabajadores en peores condiciones son los que deben tolerar más el trato desconsiderado de los empleadores. En contraste, los trabajadores más capacitados y mejor preparados ostentan un nivel más elevado de respeto ${ }^{24}$. Ello se debe especialmente al hecho que son personas que de manera relativa encontrarían más fácil un puesto de trabajo (lo común es encontrar trabajadores poco capacitados que pueden remplazarse fácilmente y que dependen más del puesto de trabajo, por lo que serían más tolerante a los maltratos).

Así púes, los más desprotegidos son los que ostentan menos mecanismos para la defensa de sus derechos y deben tolerar en mayor medida los abusos, por tanto, en esta clase de situaciones se hace importante que el Derecho Constitucional ofrezca una mayor protección a estas personas. Por lo cual, la cooperación laboral, en su aspecto nuclear debe irradiar con mayor fuerza, y, consecuentemente la órbita específica debe ser reducida o, en otras palabras, acercarse más a su núcleo, y en contraste la órbita de acción general, debe ostentar mayor protagonismo ${ }^{25}$.

\footnotetext{
24 Los trabajadores con mayor grado de formación, mayor especialidad, y que son reconocidos por las competencias que desarrollan, ostentan menor gado de subordinación respecto del empleador. Sin embargo, la mayoría de los trabajadores no están establecidos en esta categoría, sino que se encuentra en una dependencia fuerte del empleador, que se agrava como ya se mencionó, en las sociedades en las que existe un alto grado de desempleo y como mercados laborales precarios y de baja rotación, con niveles asistenciales del estado por debajo de las líneas de pobreza.

25 Es decir, que la dignidad humana se especifique y bifurque en un plexo de mecanismos que permitan su protección. Se ha de
} 
Por último, las consecuencias de la cooperación laboral son de diferente tipo. Esta situación motiva a los trabajadores a desarrollar y situar al servicio de la empresa su capacidad de trabajo; el trabajador se sentiría más motivado para el desenvolvimiento adecuado de sus funciones; existirá un desarrollo más armónico de la relación dentro de los marcos de la buena fe; el trabajador será menos reivindicatorio; tendrá la posibilidad de desarrollar sus ideas de la mejor forma posible; permitirá el desarrollo de las potencialidades del trabajador; no se crearían rencores internos que minan el adecuado desempeño de la empresa lo cual repercute en el bienestar de la empresa y la sociedad en general. Así púes, se cumple una exigencia constitucional de respeto a los derechos fundamentales. De esta forma trabajador y empresa serían beneficiados al reconfigurar la relación bajo los anteriores supuestos.

\section{REFERENCIAS BIBLIOGRÁFICAS}

ACKeRMAN, Mario (2005): Tratado de Derecho del Trabajo, (Buenos Aires, Editorial Rubinzal-Culzoni).

ALEXEI, Julio (2002): La eficacia de los derechos fundamentales entre particulares (Bogotá, Universidad Externado de Colombia).

ALEXY, Robert (2002): Teoría de los derechos fundamentales (Madrid, Centro de Estudios Políticos y Constitucionales).

AlEXY, Robert (2004): Teoría del Discurso y los Derechos Humanos (Bogotá, Universidad Externado de Colombia).

APARICIO, Joaquín (1992): Autoridad y Democracia en la Empresa (Madrid, Trota).

AUSTIN, John (1971): Cómo hacer cosas con palabras (Madrid, Paidós).

BAUMAN, Zygmunt (2006): Vida Líquida (Barcelona, Paidós).

BAYLOS, Antonio (1999): El Despido o la violencia privada del empleador (Madrid, Trotta).

Baylos, Antonio (1980): En torno al Estatuto de los Trabajadores: La prohibición de inquirir sobre la ideología, creencias y vida privada del trabajador», en AA.VV., Lecciones

efectuar una intervención jurídica que nivele, así sea por lo mínimo, la protección de los trabajadores en el tema de las relaciones laborales. La Corte Constitucional Colombiana en sentencia C 397 de 2006, preceptuó: "las normas legales deben siempre interpretarse y aplicarse a la luz de los valores, principios y derechos constitucionales y, como se anotó en estas consideraciones, el ejercicio del poder subordinante por parte del empleador está sujeto a los límites impuestos por la dignidad del trabajador, sus derechos fundamentales y los principios mínimos fundamentales establecidos en el Art. 53 de la Constitución, a los cuales se agregan los principios y derechos contenidos en los tratados y convenios internacionales en materia laboral ratificados por el Estado colombiano que forman parte integrante del bloque de constitucionalidad, conforme a lo dispuesto en los Art. 93 y 94 ibídem y la jurisprudencia de la Corte Constitucional." 
de Derecho del Trabajo. En homenaje a los profesores Bayón Chacón y Del Peso y Calvo (Madrid, Universidad Complutense).

BERMAN, Harold (1983): Los orígenes de la tradición jurídica de occidente (Cambridge, Harvard University Press).

BERNAL, Carlos (2006): El Neoconstitucionalismo a Debate (Bogotá, Universidad Externado de Colombia).

BERNAL, Carlos (2009): El Neoconstitucionalismo y la normatividad en el derecho (Bogotá, Universidad Externado de Colombia).

Cabanellas, Guillermo (1963): Contrato de Trabajo, Parte General (Buenos Aires, Omega Editores - Libreros).

CALDERón, Juan (2011): La constitucionalización del derecho privado. La verdadera historia del impacto constitucional en Colombia (Bogotá, Uniandes).

CONSTANT, Benjamín (1989): De la libertad de los antiguos comparada con la de los modernos (México, Centro de Estudios Constitucionales).

COOTER, Robert (2000): Law \& economics (New York, Addison Wesley Longman).

DUGUIT, León (1987): Las transformaciones generales del derecho privado desde el Código de Napoleón (Valparaíso, Edeval).

DWORKIN, Ronald (1993): Ética Privada e igualitarismo político (Barcelona, Paidos).

DWORKIN, Ronald (2003): Virtud soberana, La Teoría y La Práctica de la Igualdad (Barcelona, Paidos).

FerRAJolı, Luigi (2000): El garantismo y la filosofía del derecho (Bogotá, Universidad Externado de Colombia).

FERRAJOLI, Luigi (2006): Una discusión sobre derecho y democracia (Madrid, Trotta).

FERRAJOLI, Luigi (2005): Los fundamentos de los derechos fundamentales (Madrid, Trotta).

FoucAult, Michel (2003): Vigilar y Castigar (Buenos Aires, Siglo Veintiuno Editores).

HABERMAS, Jürgen (1998): Facticidad y Validez, en la indeterminación del derecho y racionalidad en la administración de justicia (Madrid, Trotta). 
HART, Herbert (2004): El concepto de derecho (Buenos Aires, Abeledo Perrot).

HERNANDEZ, Lupo (1997): Poder de Dirección del empleador (México, UNAM).

JEAMMAUD, Antoine (1992): Los derechos de información y participación en la empresa: la ciudadanía en la empresa (Madrid, Trotta).

Martinez, Daniel (1988): El Poder de Control del Empresario en la Relación Laboral (Madrid, CES).

MolinA, Cristóbal (1999): Los derechos de la persona del trabajador en la jurisprudencia del tribunal Constitucional (España, en Relaciones Laborales N. 17).

OJEDA, Antonio (2010) La deconstrucción del derecho del trabajo (Madrid, La ley).

RomAGNOLI, Humberto (1975): Autoridad y democracia en la empresa: teorías jurídicopolíticas (Madrid, Cuadernos de Derecho del Trabajo, N. 1-2).

SACHICA, Luis (1972): Nuevo constitucionalismo Colombiano (Bogotá, Temis).

SupoIT, Alain (1994): Crítica del Derecho del Trabajo, trad. José Luis Gil y Gil (Madrid, MTSS).

VALDÉs, Fernando (1992) Poderes del empresario y derechos de la persona del trabajador, en Joaquín Aparicio y Antonio Baylos, Autoridad y Democracia en la Empresa (Madrid, Trotta).

\section{JURISPRUDENCIA CITADA}

Corte Constitucional Colombiana sentencia T 125 de 1994.

Corte Constitucional Colombiana sentencia C 037 de 1996.

Corte Constitucional Colombiana sentencia T 123 de 1999.

Corte Constitucional Colombiana sentencia C 836 de 2000.

Corte Constitucional Colombiana sentencia T 982 de 2001.

Corte Constitucional Colombiana sentencia C 478 de 2003.

Corte Constitucional Colombiana sentencia C 934 de 2004. 
Corte Constitucional Colombiana sentencia T 026 de 2005.

Corte Constitucional Colombiana sentencia T 327 de 2009.

Corte Constitucional Colombiana sentencia T 237 de 2009.

Corte Constitucional Colombiana sentencia T 386 de 2009.

Corte Constitucional Colombiana sentencia T 493 de 2010.

Corte Constitucional Colombiana sentencia C 171 de 2012.

Corte Constitucional Colombiana sentencia C 253 de 2013.

Corte Constitucional Colombiana sentencia T 619 de 2013.

Corte Constitucional Colombiana sentencia C 593 de 2014.

Corte Constitucional Colombiana sentencia C 871 de 2014.

Corte Constitucional Colombiana sentencia C 237 de 2014.

Corte Constitucional Colombiana sentencia T 899 de 2014.

Corte Constitucional Colombiana sentencia T 041 de 2014. 